\title{
FURTHER ANALYSIS OF OENOTHERA BIENNIS POPULATIONS FOR INCOMPATIBILITY ALLELES ${ }^{1}$
}

\author{
Sadiq D. Al Khafaji² and Erich Steiner \\ Department of Botany, University of Michigan, Ann Arbor
}

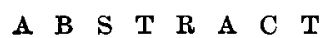

\begin{abstract}
The complex-heterozygotes of Oenothera biennis are characterized by an incompatibility allele system which acts as a part of the balanced lethal mechanism. A survey was made to determine the number and frequency of different incompatibility alleles in populations throughout south central Ohio and Indiana and in one population in northern Kentucky. No single population was found to possess more than two different alleles. Within the geographic area specified, however, at least eight different alleles occurred among the various population samples. If the incompatibility alleles are a valid index of variability for the complexes which carry them, these results suggest that individual populations are fairly uniform genetically and probably arise from relatively few colonizers. The various alleles found in these populations are believed to be relics of structurally homozygous self-incompatible progenitors which hybridized with structurally homozygous, but segmentally distinctive, self-compatible forms to give rise to the complex-heterozygotes.
\end{abstract}

Cytogenetic studies by Cleland and his associates have shown that Oenothera biennis, the weedy evening primrose found throughout much of the eastern half of the United States, consists of three distinct phylogenetic groups designated as the biennis groups 1,2 , and 3 (see Cleland, 1958 , for a summary of this work). These forms are all true-breeding translocation heterozygotes showing a circle of 14 chromosomes at meiosis. Adjacent chromosomes in the circle regularly go to opposite poles during anaphase I so that only two gametic combinations or complexes each with a different chromosomal end arrangement result. Such plants normally inbreed, but the offspring consist of only heterozygotes like the parent. Failure of homozygous combinations to occur among the progenies arising from selfpollinations is the result of a balanced lethal system. When these oenotheras are outcrossed, usually one of the complexes tends to be transmitted predominantly through the egg and the other more often through the pollen. Accordingly, the former is designated as the alpha complex and the latter as the beta complex. The alpha and beta complexes differ not only in their chromosomal end arrangement and transmission behavior, but they also produce distinctive phenotypes.

Members of the biennis group 1 are characterized by an alpha complex producing a biennis, and a beta complex producing a strigosa

${ }^{1}$ Received for publication 2 July 1969.

This study is a portion of a thesis submitted in partial fulfillment of the requirements for the Ph.D. degree, University of Michigan, by the first author.

Supported by National Science Foundation Grant G-23596 to the second author.

2 Present address: College of Agriculture, University of Bagdad, Iraq. phenotype. The biennis characters include broad. thin, dark-green leaves and slender; tapered. near-glabrous buds with appressed sepal tips Narrow, thick, gray-green leaves and short, stout pubescent buds with flared sepal tips characterize the strigosa phenotype. The majority of the alpha biennis 1 complexes which have been analyzed cytogenetically have the same chromosomal end arrangement, namely, $1.2 \quad 3.4 \quad 5 \cdot 14$ $7 \cdot 109.811 \cdot 1213 \cdot 6 .^{3}$ The beta complexes, on the other hand, are much more diverse in segmental arrangement.

When different biennis 1 races are crossed, the progenies may include offspring which bring together the alpha complex from each of the parents. The alpha-alpha hybrids are self-incompatible; they most often exhibit seven pairs of chromosomes at meiosis. The alpha biennis 1 complexes have been shown to carry a gametophytic incompatibility allele system (Steiner, $1956,1957)$. In the naturally occurring biennis 1 complex-heterozygote the alpha complex carries a self-incompatibility (SI) allele, while at the homologous locus of the beta complex a selfcompatibility (SC) allele occurs. In self-pollinations, pollen carrying the alpha complex fails to grow because the stylar tissue bears the identical allele; only the beta pollen reaches the ovules. Thus the incompatibility allele functions as a pollen lethal in self-pollinations and acts as a part of the balanced lethal system.

In a species with conventional cytogenetic behavior self-incompatibility enforces outbreeding. With a homogenic incompatibility system diversity of alleles insures that most outcrosses

${ }^{3}$ Each chromosome is represented by two numbered ends joined by a dot. 
will occur between plants carrying different alleles and therefore will be fully fertile. With few alleles in the population many of the outcrosses will be either partly or completely sterile. In the complex-heterozygotes of Oenothera, however, whether or not a population has a single or many incompatibility alleles is irrelevant in so far as the function of the allele as a pollen lethal in self-pollinations is concerned. When incompatibility was first discovered in the biennis group 1, most of the races analyzed had different alleles. Later a survey by Schooley (1965) showed that 15 out of 20 collections, representing a wide geographic area, had different SI alleles. Thus it became of interest to determine (1) to what extent individual stands possess allelic diversity, and (2) how many different alleles occur in a restricted geographic region which is only a small part of the total biennis 1 distribution. An earlier report (Steiner, 1964) presented the results of an analysis of three local stands. The present paper describes the results of a similar analysis of two additional stands as well as of small samples of 21 populations collected throughout south central Ohio and Indiana.

MATERIALs AND METHODS-The methods used for incompatibility allele analysis were the same as employed in the earlier study (Steiner, 1964). Collections from biennis group 1 populations were made at the following sites: indiana: Boston, Brown County, Greensburg, Rushville, Taylorsville. KENTUCKY: Williamstown. oHIo: Ashville, Castine, Coshocton, Donnelsville, Eaton, Eldorado, Frazeyburg, Greenville, Lancaster, Lewisburg, Mt. Sterling, Newark, Sharonville, South Bloomfield, South Charleston, South Solon, Springfield.

From 2 to 10 plants were collected at each site except in the case of the Williamstown and Sharonville populations from which 30 plants were taken. Plants were collected in early spring while still in the rosette stage; they were transplanted to pots and later moved to the experimental garden.

Each plant in the population samples was crossed as a female parent with a tester strain (alpha Hot Springs.beta Camp Peary L), a synthetic complex-heterozygote which transmits the alpha Hot Springs through the pollen at a high frequency. Since the egg parent almost always transmits its alpha complex to the offspring, progenies of such crosses consist primarily of alpha-alpha hybrids, each combining the alpha complex of a plant which was originally a member of a natural population with the alpha Hot Springs complex. These alpha-alphas are self-incompatible, since each complex carries an incompatibility allele. By intercrossing the alpha. alpha hybrids the identity or non-identity of the incompatibility alleles in the population samples can be determined. In such crosses pollen carrying the SI allele of alpha Hot Springs will not grow in the style of any plant carrying the same complex; thus only the SI alleles contributed by the population samples are under test. If pollen tubes grow, the alleles in the two complexes from the natural populations are different. If no pollen tube growth occurs, the alleles must be identical.

Alpha -alpha hybrids were readily identified by their distinctive phenotype; in many of the cultures the identification was confirmed cytologically.

All compatibility tests were made by determining pollen tube growth; earlier studies have shown that this is a reliable index of compatibility and seed set. Buds of the alpha-alpha hybrids were emasculated and bagged in early morning. The following morning when the flowers had opened they were removed from the plant, placed in vials of water, and pollinated. Each

TABLE 1. The frequencies of alpha.alphas obtained from crosses between members of the Williamstown and Sharonville populations and alpha Hot Springs.beta Camp Peary L

\begin{tabular}{|c|c|c|c|}
\hline $\begin{array}{c}\text { Culture } \\
\text { no. }\end{array}$ & $\begin{array}{c}\text { No. of } \\
\alpha \boldsymbol{\alpha} \alpha\end{array}$ & $\begin{array}{c}\% \text { of } \\
\alpha \alpha \alpha\end{array}$ & $\begin{array}{l}\text { Cytological } \\
\text { configuration } \\
\text { of } \alpha \alpha^{b}\end{array}$ \\
\hline 800 & 4 & 100 & $\odot 4,5 \mathrm{pr}$ \\
\hline 801 & 23 & 96 & $7 \mathrm{pr}$ \\
\hline 802 & 20 & 100 & $7 \mathrm{pr}$ \\
\hline 803 & 27 & 100 & $7 \mathrm{pr}$ \\
\hline 804 & 15 & 100 & $7 \mathrm{pr}$ \\
\hline 805 & 21 & 95 & $\odot 4,5$ pr \\
\hline 806 & 14 & 100 & $7 \mathrm{pr}$ \\
\hline 808 & 27 & 96 & $7 \mathrm{pr}$ \\
\hline 809 & 0 & 0 & \\
\hline 810 & 0 & 0 & \\
\hline 811 & 9 & 47 & $7 \mathrm{pr}$ \\
\hline 812 & 15 & 100 & $7 \mathrm{pr}$ \\
\hline 813 & 7 & 100 & $7 \mathrm{pr}$ \\
\hline 814 & 2 & 50 & $7 \mathrm{pr}$ \\
\hline 815 & 4 & 24 & - \\
\hline 818 & 1 & 6 & - \\
\hline 819 & 11 & 65 & - \\
\hline 820 & 10 & 100 & - \\
\hline 821 & 12 & 100 & $7 \mathrm{pr}$ \\
\hline 822 & 12 & 80 & $7 \mathrm{pr}$ \\
\hline 823 & 5 & 63 & - \\
\hline 824 & 2 & 13 & - \\
\hline 825 & 16 & 100 & - \\
\hline 826 & 5 & 83 & - \\
\hline 827 & 7 & 100 & - \\
\hline 828 & 4 & 29 & - \\
\hline 829 & 0 & 0 & \\
\hline 831 & 21 & 95 & - \\
\hline 833 & 7 & 100 & - \\
\hline 834 & 8 & 73 & - \\
\hline 835 & 10 & 91 & - \\
\hline
\end{tabular}

a Cultures 800 through 810 represent crosses of the Williamstown population and 811 through 835 those of the Sharonville population.

$\mathrm{b}$ - configuration not determined. 
TABLE 2. Compatibility relationships of the Williamstown and Sharonville alleles

\begin{tabular}{|c|c|c|}
\hline \multirow[b]{2}{*}{ Female parent ${ }^{a}$} & \multicolumn{2}{|c|}{ Pollen parent } \\
\hline & Williamstown & Sharonville \\
\hline Indianapolis $\mathbf{S}_{a}$ & + & + \\
\hline $\mathbf{S}_{\mathrm{b}}$ & + & + \\
\hline Bloomington $\mathrm{S}_{\mathrm{a}}$ & + & + \\
\hline$S_{b}$ & + & + \\
\hline Lexington $\mathrm{S}_{\mathrm{b}}$ & + & + \\
\hline$S_{c}$ & + & + \\
\hline Bestwater I & + & + \\
\hline Birch Tree I & + & + \\
\hline Birch Tree II & + & + \\
\hline Chicaginensis & + & + \\
\hline Friendship & + & + \\
\hline Hopkinsville & + & + \\
\hline Indianapolis I & + & - \\
\hline Lake & + & + \\
\hline Paducah & + & + \\
\hline Roanoke & + & + \\
\hline Williamsburg & + & + \\
\hline
\end{tabular}

see Steiner (1964) and Schooley (1965) for races and populations.

compatibility test consisted of three replicate pollinations. After pollination the flowers were incubated for $24 \mathrm{hr}$ at $26 \mathrm{C}$. The styles were then excised and fixed in a $30 \%$ alcoholic solution of IKI for $24 \mathrm{hr}$. The three styles of a test were flattened between two microscope slides and examined under a dissecting microscope for pollen tube growth. Because the pollen tubes are filled with spindle-shaped starch grains which stain readily with iodine, they are easily detected in the style.

The Williamstown and Sharonville populations were analyzed in one season, while the remainder of the collections were studied during the subsequent season.

Results-Sharonville and Williamstown populations - The composition of the progenies obtained from crosses with the members of the Williamstown and Sharonville populations is shown in Table 1 . The Williamstown population was represented by only 10 individuals as a result of transplanting losses. Two of the three cultures in which alpha-alphas did not appear were derived from the Williamstown population. Of the 31 cultures grown in the field 12 consisted of alpha-alphas exclusively, while 23 were composed of at least $50 \%$ or more alpha-alphas. The meiotic configurations of 14 of the alpha alphas were determined. Twelve showed seven pairs of chromosomes at meiosis while the remaining two showed $\odot 4^{4}$ and five pairs. The latter were derived from the Williamstown population. Thus the Williamstown population carried not only the alpha Hot Springs segmental arrangement,

"The symbol, $\odot$, denotes "a circle of." which is typical of the alpha biennis 1 complexes, but also an arrangement one interchange removed from it. The Sharonville population, insofar as its alpha complexes were determined, showed only the typical alpha biennis 1 chromosomal end arrangement.

The features which characterized the alpha. alphas phenotypically included thin, dark-green leaves, green stem tips with green papillae, thinskinned, tapered buds tending to be glabrous, and appressed sepal tips. The alpha-alphas derived from the Sharonville population were in many cases chlorotic; this was not true for the Williamstown alpha-alphas.

Compatibility tests were carried out in all combinations among the alpha-alphas derived from each population. Since reciprocal crosses give identical results, the number of compatibility tests necessary is given by the expression, $\frac{\left(n^{2}-n\right)}{2}+n$, where $n$ represents the number of different alpha-alphas. The latter term in the expression represents the self-pollinations to confirm self-incompatibility. Eight alpha-alphas were derived from the Williamstown population, 20 from the Sharonville population. Within each of these groups the compatibility tests proved to be negative, indicating that all members of the population sample carried the same incompatibility allele. Crosses between alpha-alphas derived from the Williamstown population and those derived from the Sharonville population proved to be compatible. Thus the incompatibility alleles characterizing the two populations were different.

The identities of the Williamstown and Sharonville alleles with those of the populations previously analyzed (Steiner, 1964) and with those of a number of biennis 1 races studied by Schooley (1965) were also tested. The results of these tests are shown in Table 2. All alleles proved to be different with one exception. The latter is a discrepancy which remains unexplained. Tests of the Sharonville allele with the two found in the Indianapolis population analyzed earlier (tentatively designated $\mathbf{S}_{\mathrm{a}}$ and $\mathbf{S}_{\mathrm{b}}$ ) (Steiner, 1964) showed these alleles to differ. The $S_{a}$ allele from the Indianapolis population had previously been shown to be identical to the allele of an earlier Indianapolis collection made by Cleland and here designated as Indianapolis I. However, the test of the Sharonville allele with the Indianapolis I allele was negative, but it was positive with the $S_{a}$ allele. The tests were repeated a number of times and consistently gave the same results.

Other population samples - The results of crosses between plants collected from populations throughout south central Ohio and Indiana and alpha Hot Springs.beta Camp Peary $L$ are summarized in Table 3 . Twenty-four out of 84 
TABLE 3. The frequencies of alpha.alphas obtained from crosses between the Ohio and Indiana population samples and alpha Hot Springs - beta Camp Peary $L$

\begin{tabular}{|c|c|c|c|c|}
\hline $\begin{array}{l}\text { Collection } \\
\text { site }\end{array}$ & $\begin{array}{l}\text { Cul- } \\
\text { ture } \\
\text { no. }\end{array}$ & $\begin{array}{c}\text { No. } \\
\text { of } \\
\alpha \alpha\end{array}$ & $\begin{array}{c}\% \\
\text { of } \\
\alpha \alpha\end{array}$ & $\begin{array}{l}\text { Cytological } \\
\text { configuration } \\
\text { of } \alpha \alpha\end{array}$ \\
\hline \multirow{6}{*}{ Ashville } & 200 & 9 & 90 & - \\
\hline & 201 & 9 & 90 & - \\
\hline & 202 & 6 & 60 & - \\
\hline & 203 & 10 & 100 & - \\
\hline & 204 & 10 & 100 & - \\
\hline & 205 & 10 & 100 & - \\
\hline \multirow{4}{*}{ Boston } & 206 & 5 & 50 & - \\
\hline & 207 & 0 & 0 & 一 \\
\hline & 208 & 9 & 90 & $\odot 4, \odot 4,3$ pr \\
\hline & 209 & 6 & 60 & $\odot 4, \odot 4,3 \mathrm{pr}$ \\
\hline \multirow[t]{7}{*}{ Brown County } & 210 & 10 & 100 & $-\quad-$ \\
\hline & 211 & 10 & 100 & $7 \mathrm{pr}$ \\
\hline & 212 & 9 & 90 & - \\
\hline & 213 & 10 & 100 & $7 \mathrm{pr}$ \\
\hline & 214 & 2 & 20 & $7 \mathrm{pr}$ \\
\hline & 215 & 0 & 0 & - \\
\hline & 216 & 7 & 70 & $7 \mathrm{pr}$ \\
\hline \multirow[t]{4}{*}{ Castine } & 217 & 0 & 0 & - \\
\hline & 218 & 3 & 30 & - \\
\hline & 219 & 0 & 0 & - \\
\hline & 220 & 0 & 0 & - \\
\hline \multirow[t]{2}{*}{ Coshocton } & 221 & 10 & 100 & $7 \mathrm{pr}$ \\
\hline & 222 & 0 & 0 & - \\
\hline \multirow[t]{5}{*}{ Donnelsville } & 223 & 9 & 90 & - \\
\hline & 224 & 10 & 100 & - \\
\hline & 225 & 9 & 100 & $\odot 4, \odot 4,3 \mathrm{pr}$ \\
\hline & 226 & 7 & 70 & - \\
\hline & 227 & 0 & 0 & - \\
\hline \multirow[t]{3}{*}{ Eaton } & 228 & 10 & 100 & $\odot 4, \odot 6,2 \mathrm{pr}$ \\
\hline & 229 & 10 & 100 & $\odot 4, \odot 6,2 \mathrm{pr}$ \\
\hline & 230 & 10 & 100 & $\odot 4, \odot 6,2 \mathrm{pr}$ \\
\hline \multirow[t]{4}{*}{ Eldorado } & 231 & 0 & 0 & - \\
\hline & 232 & 0 & 0 & - \\
\hline & 233 & 10 & 100 & $7 \mathrm{pr}$ \\
\hline & 234 & 9 & 90 & $7 \mathrm{pr}$ \\
\hline \multirow[t]{3}{*}{ Frazeyburg } & 235 & 10 & 100 & $7 \mathrm{pr}$ \\
\hline & 236 & 0 & 0 & - \\
\hline & 237 & 0 & 0 & - \\
\hline \multirow[t]{4}{*}{ Greenville } & 238 & 1 & 100 & 一 \\
\hline & 239 & 0 & 0 & - \\
\hline & 240 & 0 & 0 & - \\
\hline & 241 & 0 & 0 & - \\
\hline \multirow[t]{4}{*}{ Lewisburg } & 242 & 5 & 55 & - \\
\hline & 243 & 2 & 20 & - \\
\hline & 244 & 10 & 100 & $7 \mathrm{pr}$ \\
\hline & 245 & 9 & 90 & $7 \mathrm{pr}$ \\
\hline \multirow[t]{3}{*}{ Mt. Sterling } & 246 & 10 & 100 & - \\
\hline & 247 & 10 & 100 & $\odot 4, \odot 4,3 \mathbf{p r}$ \\
\hline & 248 & 9 & 90 & $\odot 4, \odot 4,3 \mathrm{pr}$ \\
\hline \multirow[t]{2}{*}{ Newark } & 249 & 10 & 100 & $\odot 6,4 \mathrm{pr}$ \\
\hline & 250 & 10 & 100 & $\odot 6,4 \mathrm{pr}$ \\
\hline \multirow[t]{4}{*}{ Lancaster } & 251 & 9 & 100 & $7 \mathrm{pr}$ \\
\hline & 252 & 10 & 100 & $7 \mathrm{pr}$ \\
\hline & 253 & 5 & 100 & $7 \mathrm{pr}$ \\
\hline & 254 & 7 & 70 & $7 \mathrm{pr}$ \\
\hline \multirow[t]{3}{*}{ Greensburg } & 255 & 3 & 30 & - \\
\hline & 256 & 6 & 60 & $7 \mathrm{pr}$ \\
\hline & 257 & 0 & $\mathbf{0}$ & - \\
\hline
\end{tabular}

TABLE 3. Continued

\begin{tabular}{|c|c|c|c|c|}
\hline $\begin{array}{l}\text { Collection } \\
\text { site }\end{array}$ & $\begin{array}{l}\text { Cul- } \\
\text { ture } \\
\text { no. }\end{array}$ & $\begin{array}{l}\text { No. } \\
\text { of } \\
\alpha \alpha\end{array}$ & $\begin{array}{l}\% \\
\text { of } \\
\alpha \alpha\end{array}$ & $\begin{array}{l}\text { Cytological } \\
\text { configuration } \\
\text { of } \alpha \alpha\end{array}$ \\
\hline \multirow[t]{7}{*}{ South Bloomfield } & 258 & 8 & 80 & $\odot 4, \odot 4,3 \mathrm{pr}$ \\
\hline & 259 & 10 & 100 & $\odot 4, \odot 4,3 \mathrm{pr}$ \\
\hline & 260 & 10 & 100 & $\odot 4, \odot 4,3$ pr \\
\hline & 261 & 10 & 100 & $\odot 4, \odot 4,3 \mathrm{pr}$ \\
\hline & 262 & 10 & 100 & $\odot 4, \odot 4,3 \mathrm{pr}$ \\
\hline & 263 & 10 & 100 & $\odot 4, \odot 4,3 \mathbf{p r}$ \\
\hline & 264 & 10 & 100 & $\odot 4, \odot 4,3 \mathrm{pr}$ \\
\hline \multirow[t]{2}{*}{ Rushville } & 265 & 10 & 100 & 7 pr \\
\hline & 266 & 0 & 0 & - \\
\hline \multirow[t]{5}{*}{ South Charleston } & 267 & 10 & 100 & - \\
\hline & 268 & 10 & 100 & $7 \mathrm{pr}$ \\
\hline & 269 & 9 & 100 & $7 \mathrm{pr}$ \\
\hline & 270 & 7 & 100 & - \\
\hline & 271 & 11 & 84 & $\odot 4, \odot 4,3$ рг \\
\hline \multirow[t]{4}{*}{ South Solon } & 272 & 0 & 0 & - \\
\hline & 273 & 0 & 0 & - \\
\hline & 274 & 0 & 0 & - \\
\hline & 275 & 0 & 0 & 一 \\
\hline \multirow[t]{5}{*}{ Springfield } & 276 & 0 & 0 & 一 \\
\hline & 277 & 3 & 30 & - \\
\hline & 278 & 9 & 90 & $\odot 6,4 \mathrm{pr}$ \\
\hline & 279 & 0 & 0 & - \\
\hline & 280 & 10 & 100 & $\odot 4, \odot 4,3 \mathrm{pr}$ \\
\hline \multirow[t]{3}{*}{ Taylorsville } & 281 & 7 & 70 & $\odot 6,4 \mathrm{pr}$ \\
\hline & 282 & 0 & 0 & - \\
\hline & 283 & 0 & 0 & - \\
\hline
\end{tabular}

cultures lacked alpha-alphas. In certain of the cultures in which alpha-alphas occurred, this complex combination was reduced in vigor to varying degrees. Thus the number of flowers available for compatibility tests was limited in some cases. On the whole, however, the alpha. alphas were vigorous plants with little or no chlorosis.

Although the phenotype described previously as characteristic of alpha-alphas was found in most cultures, in a few cases the alpha.alphas showed characters atypical for this complex combination. For example, the alpha-alphas derived from the Newark population had darkred stems, while those from the Mt. Sterling population exhibited red instead of green papillae. Buds of alpha-alphas from the Eaton population were more pubescent than typical for alpha.alphas.

The population samples showed more variability in segmental arrangement of the alpha complexes than expected. As Table 3 shows, many of the alpha-alphas exhibited a meiotic configuration of one or more small circles rather than seven bivalents. Thus these alpha complexes ranged from two to three interchanges removed from the typical alpha biennis 1 chromosomal end arrangement. With two exceptions (South Charleston and Springfield) the configurations, in so far as they were determined, were the same for all plants of a particular collection site, which 
suggests, although does not prove, that members of a local stand have alpha complexes with the same segmental arrangement.

The results of the compatibility tests between the alpha-alpha hybrids derived from the population samples are summarized in Table 4. To test each culture with every other culture would have involved a minimum of some 2,000 tests; the length of the flowering period did not permit an analysis of this extent. Variations in time of blooming, the reduced number of flowers produced on depauperate plants in certain cultures also restricted the number of compatibility tests which could be carried out. Nevertheless, it was possible to group most of the collections into incompatibility types by employing the principle that two alpha-alphas which are incompatible with a third must be incompatible with each other and therefore carry the same incompatibility allele. Of the 60 cultures with alpha-alpha complex combinations, 39 were classified with certainty. In two cases one or two tests were lacking; another eight were insufficiently tested to allow other than a very tentative grouping. The classification is shown in Table 4 . Each member within a group was shown to be incompatible, directly or indirectly, with all other members of the same group.

Using the same approach, compatibility was demonstrated between members of different

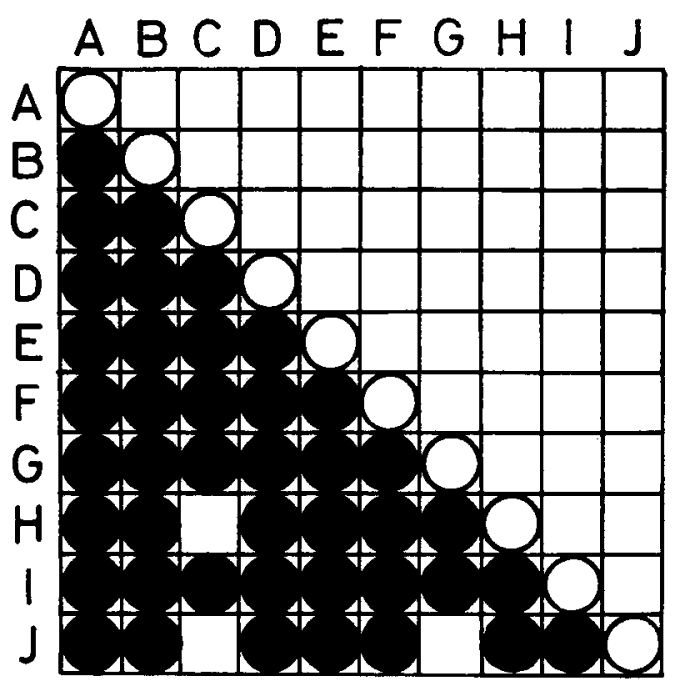

1

Fig. 1. Compatibility groups found among the population samples analyzed and their compatibility relationships. Open circle, incompatible; solid circle, compatible; open square, not tested.

groups; the inter-group tests are shown in Fig. 1. One or more members of a group were tested with at least one member of all other groups

TABLE 4. Incompatibility grouping of population samples based on compatibility tests between alpha alpha hybrids

\begin{tabular}{|c|c|c|c|c|c|}
\hline $\begin{array}{l}\text { Incompati- } \\
\text { bility } \\
\text { group }\end{array}$ & $\begin{array}{c}\text { Culture } \\
\text { no. }\end{array}$ & Collection & $\begin{array}{l}\text { Incompati- } \\
\text { bility } \\
\text { group }\end{array}$ & $\begin{array}{c}\text { Culture } \\
\text { no. }\end{array}$ & Collection \\
\hline A & $\begin{array}{l}200 \\
201 \\
221 \\
223 \\
224 \\
226 \\
238 \\
244 \\
245 \\
267 \\
268 \\
269 \\
270 \\
208 \\
209 \\
235 \\
258 \\
259 \\
260 \\
261 \\
262 \\
263 \\
264\end{array}$ & $\begin{array}{l}\text { Ashville } \\
\text { “ } \\
\text { Coshocton } \\
\text { Donnelsville } \\
\text { “ } \\
\text { Greenville } \\
\text { Lewisburg } \\
\text { “ } \\
\text { South Charleston } \\
\text { " } \\
\text { “ } \\
\text { Boston } \\
\text { " } \\
\text { Frazeyburg } \\
\text { South Bloomfield } \\
\text { " } \\
\text { " } \\
\text { " } \\
\text { " }\end{array}$ & $\begin{array}{l}\mathrm{G} \\
\mathrm{H}^{\mathrm{a}} \\
\mathrm{I} \\
\mathrm{J}^{\mathrm{b}}\end{array}$ & $\begin{array}{l}211 \\
212 \\
213 \\
225 \\
246 \\
248 \\
281 \\
247 \\
271 \\
251 \\
252 \\
254 \\
255 \\
256 \\
265 \\
233 \\
234 \\
280\end{array}$ & $\begin{array}{l}\text { Brown County } \\
\text { " } \\
\text { Donnelsville } \\
\text { Mt. Sterling } \\
\text { " } \\
\text { Taylorsville } \\
\text { Mt. Sterling } \\
\text { South Charleston } \\
\text { Lancaster } \\
\text { " } \\
\text { Greensburg } \\
\text { " } \\
\text { Rushville } \\
\text { Eldorado } \\
\text { " } \\
\text { Springfield }\end{array}$ \\
\hline
\end{tabular}

a One test lacking.

b Two tests lacking. 
TABLE 5. Tentative groupings of incompletely tested population samples ${ }^{\mathrm{B}}$

\begin{tabular}{|c|c|c|}
\hline $\begin{array}{l}\text { Culture } \\
\text { no. }\end{array}$ & Collection & Comment \\
\hline 228 & Eaton & The Eaton and Newark cultures \\
\hline 229 & & show incompatibility reactions to \\
\hline 230 & " & both groups B and E. \\
\hline 249 & Newark & \\
\hline 250 & " & \\
\hline 206 & Boston & $\begin{array}{l}\text { Shown to differ from other Boston } \\
\text { cultures, but otherwise not tested. }\end{array}$ \\
\hline 277 & $\begin{array}{l}\text { Spring- } \\
\text { field }\end{array}$ & $\begin{array}{l}\text { Differs from Springfield culture } 280 \\
\text { and group A; otherwise not tested. }\end{array}$ \\
\hline 281 & $\begin{array}{l}\text { Taylors- } \\
\text { ville }\end{array}$ & $\begin{array}{l}\text { Differs from groups } \mathrm{F} \text { and } \mathrm{H} \text {; } \\
\text { otherwise not tested. }\end{array}$ \\
\hline
\end{tabular}

a The remaining cultures with alpha-alphas either did not come into flower or the plants were depauperate and produced too few flowers to make testing feasible.

except where a blank square is shown.

It should also be noted that the alpha.alphas derived from the Eaton and Newark collections were inconsistent in their incompatibility behavior in that they were incompatible with members of both groups B and E. The compatibility behavior of all members of groups $B$ and $E$ is otherwise entirely consistent with this grouping. For this reason the collections from Eaton and Newark have been placed in a separate category.

In summary, most of the population samples in this study fall into eight incompatibility groups; i.e., at least eight different incompatibility alleles are found among these populations (Table 5). One allele is found in six different populations, two others in three, one in two, and the remainder in one. No single population carries more than two different alleles insofar as these samples indicate. The geographic distri-

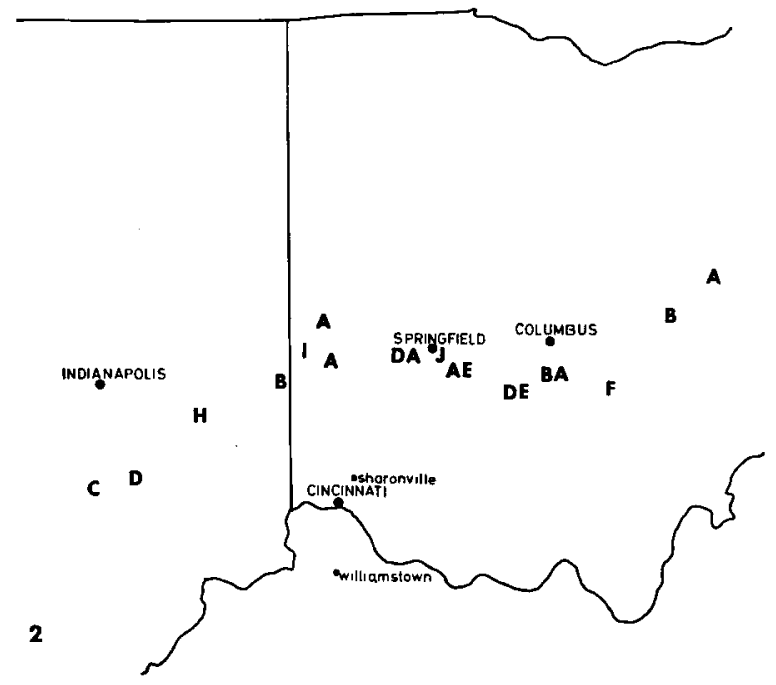

Fig. 2. Geographic distribution of the different incompatibility types. bution of the alleles is shown in Fig. 2. The tentative incompatibility groups $\mathrm{H}$ and $\mathrm{J}$ are included. Unfortunately tests to determine the identity of these alleles in relation to those analyzed in previous seasons were not carried out because of difficulties encountered in maintaining different allelic stocks through successive generations.

Discussion-A survey of incompatibility allele diversity in the biennis 1 forms was undertaken with the hope of gaining additional insight into the structure and composition of local populations of these plants. In light of the genetic nature of the complex-heterozygote it seemed reasonable to assume that the incompatibility locus can serve as an index of diversity of the alpha biennis 1 complexes; in other words, two individuals with the same incompatibility allele most likely have identical alpha complexes, particularly if they are members of the same population. Since no single population sample has yielded more than two different SI alleles, a local stand appears typically to be fairly uniform in genetic composition, representing as few as one or two pure lines or "races," according to the terminology of Cleland. This suggests that a new habitat is usually colonized by relatively few plants. Even a single plant can be an effective colonizer, because the complex-heterozygotes are self-pollinating and, if at all vigorous, prolific seed producers. That a local stand of biennis 1 plants has limited variability is also supported by cytological evidence. Only three population samples showed more than one kind of chromosomal configuration; thus it seems unlikely that more than two different segmental arrangements of the alpha complex occur in an individual population.

Although a particular population exhibits considerable uniformity, the populations within a given geographical area (topodeme) show considerable diversity of incompatibility alleles. At least 8 , and very likely 10 different incompatibility alleles occur in a region making up only a small fraction of the biennis 1 range which extends over the central and lower Midwest and into the Southeast. It is difficult to assess the significance of the geographic distribution of these alleles as shown in Fig. 2. Certain alleles, for example those of groups $\mathrm{A}$ and $\mathrm{B}$, are distributed throughout most of the region sampled, while others, represented by such groups as $\mathbf{F}, \mathbf{G}, \mathbf{H}$, and $I$, are each found in only a single population. These latter alleles could be characteristic of adjacent regions which were not sampled. The different SI alleles may be components of genetically distinctive alpha complexes which differ in adaptive value and therefore vary in frequency in a particular region.

The variability in incompatibility alleles throughout the region is paralleled to a limited extent by variability in segmental arrangement as indicated by different chromosomal configura- 
tions at meiosis in the the alpha.alpha hybrids. At least four different segmental arrangements occur among the alpha biennis 1 complexes of the region.

Field observations suggest that the biennis 1 populations are generally limited in size, numbering from a few hundred to - several thousand individuals. Such stands are usually discontinuous with one another. Collecting experience has shown that populations do not necessarily occur wherever a roadside or old field habitat appears suitable for these weeds. In contrast, the probability that a stand will be found along a railroad right of way is very high. A comparison of these habitats from the standpoint of establishment and persistence of the oenotheras should be an interesting study. Since the railroad roadbed does not seem to be a highly variable habitat from place to place, it is difficult to attribute the variation in both incompatibility alleles and segmental arrangement to selection, particularly in a limited geographic area.

The validity of utilizing the incompatibility alleles as an index of similarity between alpha complexes in the biennis 1 populations depends upon the manner in which the allelic diversity arose. A hypothesis was previously proposed (Steiner, 1956) to account for the origin of the biennis 1 complex-heterozygotes through hybridization of two structurally homozygous but segmentally distinctive populations, one of which was self-compatible, the other self-incompatible. If these populations came into extensive contact and hybrids formed repeatedly, one would expect most of the hybrids to carry different SI alleles, since the SI progenitor population should have typically carried a large number of different incompatibility alleles. According to this view present-day biennis 1 forms, having arisen from repeated hybridization, should show considerable incompatibility allele diversity. There is, however, no obvious advantage for the population to carry the many different alleles, because the complexheterozygotes are self-pollinating and the SI allele functions as a part of the balanced lethal mechanism and not to enforce outbreeding as in its conventional context.

An alternative hypothesis is that the biennis 1 forms arose from a single or relatively few hybridizations between the progenitor populations, the present allelic diversity not being primarily relic, but having resulted from repeated mutation of the incompatibility locus in the complex heterozygotes. If such mutations occur with appreciable frequency, the incompatibility allele may not be a reliable indicator of the identity of the alpha complexes. However, the work of Lewis (1951) suggests that the frequency of mutation from one SI allele to another is very low. Further, the two progenitor populations must have been isolated during their cytogenetic differentiation. The fact that they came into contact implies expansion of the range of one or both of these populations. Under these circumstances it is difficult to imagine that the range expansion would stop precisely short of overlap of the two populations and thus restrict the possibility of hybridization. Therefore, the hypothesis that the SI alleles in the biennis 1 forms are relics seems more acceptable.

In summary, the present evidence indicates that the biennis group 1 consists of a collection of relatively small, discontinuous populations, each of which is fairly uniform genetically. The different populations, however, even in a limited geographic area are diverse, at least within the limits which characterize the biennis phenotype. It is clear that the incompatibility allele is only a single index of genetic diversity and that additional criteria are needed for a more precise characterization of the genetic composition of these populations. Further, the size of the population sample which can feasibly be analyzed for incompatibility alleles is limited. The same disadvantage applies to the analysis of chromosomal segmental arrangements. Work is therefore in progress to devise other methods of describing the genetic variability of these populations so that a better understanding of their establishment, reproduction, and extinction can be obtained.

\section{LITERATURE CITED}

Cleland, R. E. 1958. The evolution of the North American oenotheras of the "biennis" group. Planta 51: $379-398$

LEwIs, D. 1951. Structure of the incompatibility allele. III. Types of spontaneous and induced mutation. Heredity 5: $399-414$.

Schooley, J. B. 1965. The incompatibility mechanism of the biennis group 1 races of Oenothera. Genetics 52: $145-152$

Steiner, E. 1956. New aspects of the balanced lethal mechanism in Oenothera. Genetics 41: 486-500.

- 1957. Further evidence of an incompatibility allele system in the complex-heterozygotes of Oenothera. Amer. J. Bot. 44: 582-585.

- 1964. Incompatibility studies in Oenothera: The distribution of $S_{1}$ alleles in biennis 1 populations. Evolution 18: 370-378. 